\title{
Nasogastric Tube Syndrome; Severe Complication Associated with Nasointestinal ileus Tube: A Case Report and Literature Review
}

Kenkichiro Taira ( $\square$ kenkichiro.t@tottori-u.ac.jp )

Tottori university

Kazunori Fujiwara

Tottori university

Fukuhara Takahiro

Tottori university

Satoshi Koyama

Tottori university

Tsuyoshi Morisaki

Tottori University: Tottori Daigaku

Ryohei Donishi

Tottori university

Hiromi Takeuchi

Tottori university

\section{Case report}

Keywords: upper airway obstruction, nasogastric tube syndrome, nasointestinal ileus tube, laryngoscope, vocal paralysis

Posted Date: December 23rd, 2020

DOl: https://doi.org/10.21203/rs.3.rs-131517/v1

License: (c) (1) This work is licensed under a Creative Commons Attribution 4.0 International License. Read Full License 


\section{Abstract}

\section{Background}

Nasogastric tube syndrome induced by nasointestinal ileus tube is uncommon complication and potentially life-threatening complication. The early detection and proper treatment for NGTS is necessary.

\section{Case presentaion}

We describe a case of a 78-year-old patient with this syndrome induced by nasointestinal ileus tube. The symptom of this syndrome was improved by immediate proper management. Immediate removal of tube and early recognition of symptom are the first step in treatment for this syndrome, in addition to initiation of steroids, proton pomp inhibitor and antibiotic therapy. The cause of NGTS is supposed to be a continuous pressure on hypopharynx and cervical esophagus.

\section{Conclusions}

Nasogastric tube syndrome should be considered in patients not only with nasogastric tube but also nasointestinal ileus tube. Early diagnosis and proper management for NGTS are important

\section{Background}

Recently, nasogastric tube syndrome (NGTS) which is one of serious complications induced by nasogastric tube (NGT) has been often reported. ${ }^{[1-3]}$ The early detection and proper treatment for NGTS is necessary because NGTS often become serious to progress into acute upper airway obstruction caused by bilateral vocal paralysis or laryngeal infection. NGTS induced by nasointestinal ileus tube is also reported in addition to NGTS induced by NGT. ${ }^{[4]}$ [5]

\section{Case Presentation}

The patients was 78 years old man. He was admitted to Sanin Rosai hospital for treatment of aspiration pneumonia. His medical condition at administration was a little nutrition, his height was $151 \mathrm{~cm}$ and body weight $39.2 \mathrm{~kg}$. Laboratory tests showed lymphocyte cell count of $10.6 \times 109 / \mu \mathrm{L}$, albumin level of $2.3 \mathrm{~g} / \mathrm{dL}$ His activities of daily living was bedridden due to spinal disease. At administration, ileus was suspected from physiological examination and thoracioabdominal X-ray. A nasointestinal ileus tube (18Fr, 5.3mm in diameter) was placed through left nasal cavity. (figure 1) Two days later, the symptom of ileus was being improved. Three days later, hoarseness and wheezing were found at round of nutrition support team (NST). NST member was consisted of physicians, nutritionist, pharmacist, speech therapist and nurse. The upper airway obstruction was suspected and observed immediately with flexible laryngoscope by an otolaryngologist. Left arytenoid edema and reddish was found in larynx. Left vocal cord was paralysed and fixed. (figure 2) The nasointestinal ileus tube was removed immediately. Intravenous steroids and proton pomp inhibitor along with antibiotic therapy were initiated. (figure 3) Six 
hours after removal, the arytenoid edema is improved significantly. The risk of upper airway obstruction was decreasing and tracheostomy was avoided. Seven days after removal, the symptom of complication was improved significantly. Oral intake was restarted based on the examination of swallowing function. (figure 4) Eleven days after removal, the treatment for aspiration pneumonia was ended and the discharge was completed without any sequelae.

\section{Discussion And Conclusions}

Though more NGTS cases attributing to NGT have been reported, only two reports have shown NGTS induced by nasointestinal ileus tube except our case, ${ }^{[1-8]}$ The proposed mechanisms is tissue injury caused by continuous pressure on the region of physiologic narrowing between hypopharynx and cervical esophagus. ${ }^{[2,9,10]}$ Another possible mechanism would be a relationship between NGTS and gastroesophageal reflux due to supine position of the patient. ${ }^{[1,11]}$ First of all, appropriate therapy is immediate removal of tube to prevent the pressure induced by nasointestinal ileus tube. ${ }^{[5,6,12]}$ In our study, the medication from early stage treatment was important because the mechanism of arytenoid edema would be caused by the infection from posterior cricoarytenoid muscle which was injured. $[1,9,10]$ In addition, we speculate that the mechanism of vocal disfunction was a temporary paralysis induced by the reversible injure of posterior cricoarytenoid muscle because we could early recognize the laryngeal symptom. Clinical course; development of NGTS symptom during intubation and improvement of NGTS symptom after extubation, also shows that this case was a complication induced by NGT. There are several NGTS reports that the tube diameter is same size as $18 \mathrm{Fr}$ in our case. ${ }^{[1,2]}$ It is suggested that a narrow tube diameter is better to be used, considering the mechanism. ${ }^{[5]}$

NGTS in our case developed three days after tube replacement, which is shorter than other report; the syndrome had been reported five days or more after tube placement. ${ }^{[1,3,6,10,13]}$ However, there is a report that the symptom have developed within 12 hours after tube replacement. ${ }^{[12]}$ Therefore, the thorosic symptom of hoarseness, wheezing in patients with the replacement of NGT should be payed attention due to a risk of acute deterioration in short duration. Especially, immunocompromised states have been reported to be risk factors for NGTS ${ }^{[2,3,13,14]}$ Usually, the nutritional status in patients with NGT or nasointestinal ileus tube deteriorates due to lack of oral intake. In our case, immunocompromised status was supposed because the physical findings and laboratory tests indicated the condition of malnutrition. In our case, the early detection and immediate treatment for NGTS could be performed without any sequelae. However, the symptom of NGTS potentially become severe in cases of tracheotomy, unfortunately death due to upper airway obstruction. ${ }^{[12]}$ Thus, the condition of vocal cord and larynx should be examined carefully. A vocal paralysis associated with all NGTS is a most common observation confirmed by laryngoscope. ${ }^{[12]}$ Immediately after suspicion of NGTS such as hoarseness and wheezing in patients with nasointestinal ileus tube, laryngoscopy is mandatory. ${ }^{[12]}$ Nasointestinal ileus tube is usually used by gastroenterologists who are not used to medical assessment of larynx and pharynx. In 
addition, there are few reports about NGTS associated with nasointestinal ileus tube. Thus, NGTS associated with nasointestinal ileus tube is not known well.

Patients with nasointestinal ileus tube might be not able to appeal the symptom of NGTS immediately and accurately due to low ADL level or poor general condition as same as in our case. An early recognition of NGTS symptoms is important. In our case, an early recognition of hoarseness at NST round might avert a life-threatening condition of NGTS. Nasointestinal ileus tube is an effective treatment device on ileus. ${ }^{[15]} \mathrm{A}$ more narrow tube diameter will be ideally chosen to reduce the pressure against the organization. ${ }^{[1]}$ However, thick tube diameter of nasointestinal ileus tube sometimes have to be used to treat ileus more effectively. ${ }^{[16,17]}$ Consequently, when nasointestinal ileus tube is used, systems for early diagnosis and proper management should be built in addition to wide knowledge for the presence of NGTS.

In conclusion, NGTS should be considered in patients not only with NGT but also with nasointestinal ileus tube. Early diagnosis and proper management for NGTS are important to prevent life-threatening case.

\section{List Of Abbreviations}

ADL; activities of daily life,

NGTS; nasogastric tube syndrome,

NGT; nasogastric tube,

NST; nutrition support team

\section{Declarations}

\section{Ethics approval and consent to participate}

Not applicable

\section{Consent for publication}

Written and signed Consent for publication has been obtained from the patients

\section{Availability of data and materials}

Not applicable

\section{Competing interests}


The authors declare that they have no competing interests

\section{Funding}

This case report was not supported by relevant funds.

\section{Authors' contributions}

KT drafted the manuscript. KT performed the clinical work-up and therapy. KF participated in designing the report and revised the language and grammar of the manuscript. TF, KS, TM, RD and HT critically revised the manuscript. All authors read and approved the final manuscript.

\section{Acknowledgements}

Not applicable

\section{Authors' information (optional)}

${ }^{1}$ Division of Otolaryngology, Head and Neck Surgery, Department of Sensory and Motor Organs, School of Medicine, Faculty of Medicine, Tottori University, Yonago 683-8504, Japan

${ }^{2}$ Japan Organization of Occupational Health and Safety Sanin Rosai Hospital otolaryngology Yonago 683-8605, Japan

\section{References}

1. Nehru VI, Al Shammari HJ, Jaffer AM: Nasogastric tube syndrome: the unilateral variant. Med Princ Pract 2003, 12(1):44-46.

2. Sofferman RA, Haisch CE, Kirchner JA, Hardin NJ: The nasogastric tube syndrome. Laryngoscope 1990, 100(9):962-968.

3. Apostolakis LW, Funk GF, Urdaneta LF, McCulloch TM, Jeyapalan MM: The nasogastric tube syndrome: two case reports and review of the literature. Head Neck 2001, 23(1):59-63.

4. Sanaka M, Kishida S, Yoritaka A, Sasamura Y, Yamamoto T, Kuyama Y: Acute upper airway obstruction induced by an indwelling long intestinal tube: attention to the nasogastric tube syndrome. J Clin Gastroenterol 2004, 38(10):913.

5. Sano N, Yamamoto M, Nagai K, Yamada K, Ohkohchi N: Nasogastric tube syndrome induced by an indwelling long intestinal tube. World J Gastroenterol 2016, 22(15):4057-4061. 
6. Marcus EL, Caine Y, Hamdan K, Gross M: Nasogastric tube syndrome: a life-threatening laryngeal obstruction in a 72-year-old patient. Age Ageing 2006, 35(5):538-539.

7. Vielva del Campo B, Moráis Pérez D, Saldaña Garrido D: Nasogastric tube syndrome: a case report. Acta Otorrinolaringol Esp 2010, 61(1):85-86.

8. Harmon J, Balakrishnan K, de Alarcon A, Hart CK: The nasogastric tube syndrome in infants. Int J Pediatr Otorhinolaryngol 2014, 78(5):882-884.

9. Friedman M, Baim H, Shelton V, Stobnicki M, Chilis T, Ferrara T, Skolnik E: Laryngeal injuries secondary to nasogastric tubes. Ann Otol Rhinol Laryngol 1981, 90(5 Pt 1):469-474.

10. Isozaki E, Tobisawa S, Naito R, Mizutani T, Hayashi H: A variant form of nasogastric tube syndrome. Intern Med 2005, 44(12):1286-1290.

11. Dotson RG, Robinson RG, Pingleton SK: Gastroesophageal reflux with nasogastric tubes. Effect of nasogastric tube size. Am J Respir Crit Care Med 1994, 149(6):1659-1662.

12. Brousseau VJ, Kost KM: A rare but serious entity: nasogastric tube syndrome. Otolaryngol Head Neck Surg 2006, 135(5):677-679.

13. Sofferman RA, Hubbell RN: Laryngeal complications of nasogastric tubes. Ann Otol Rhinol Laryngol 1981, 90(5 Pt 1):465-468.

14. Wolff AP, Kessler S: latrogenic injury to the hypopharynx and cervical esophagus: an autopsy study. Ann Otol Rhinol Laryngol 1973, 82(6):778-783.

15. Shi $Y$, Zhang XP, Qin $H, Y u$ YJ: Naso-intestinal tube is more effective in treating postoperative ileus than naso-gastric tube in elderly colorectal cancer patients. Int J Colorectal Dis 2017, 32(7):10471050 .

16. Li L, Xue B, Zhao Q, Xie HQ, Luan XR, Cui Q: Observation on the curative effect of long intestinal tube in the treatment of phytobezoar intestinal obstruction. Medicine (Baltimore) 2019, 98(11):e14861.

17. Li RH, Li DC, Lv XP, Quan B: Radiophotographically Controlled Nasointestinal Intubation to Treat Recurrent Postoperative Adhesive lleus. Cell Biochem Biophys 2015, 72(2):509-514.

\section{Figures}




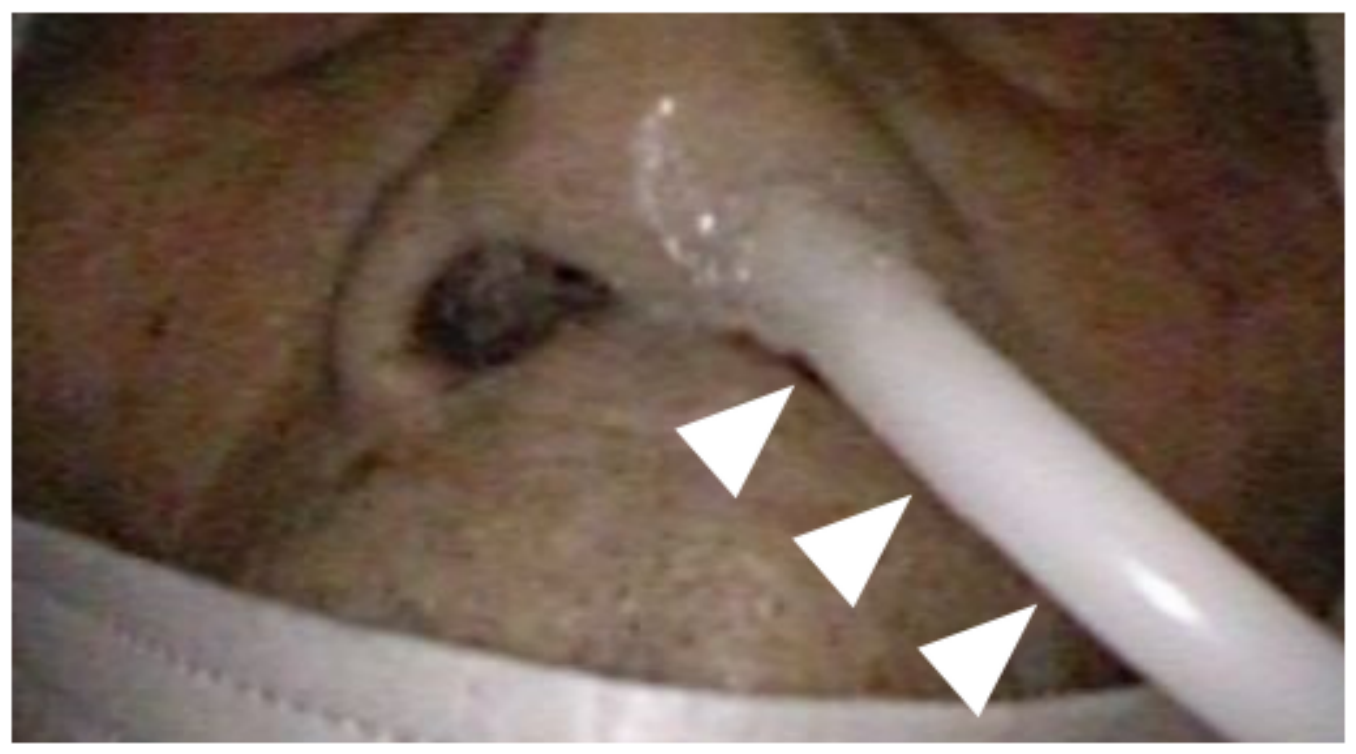

Figure 1

title: nasointestinal ileus tube $(18 \mathrm{Fr}, 5.3 \mathrm{~mm}$ in diameter)at the time of onset Legend: nasointestinal ileus tube $(18 \mathrm{Fr}, 5.3 \mathrm{~mm}$ in diameter) was placed through left 


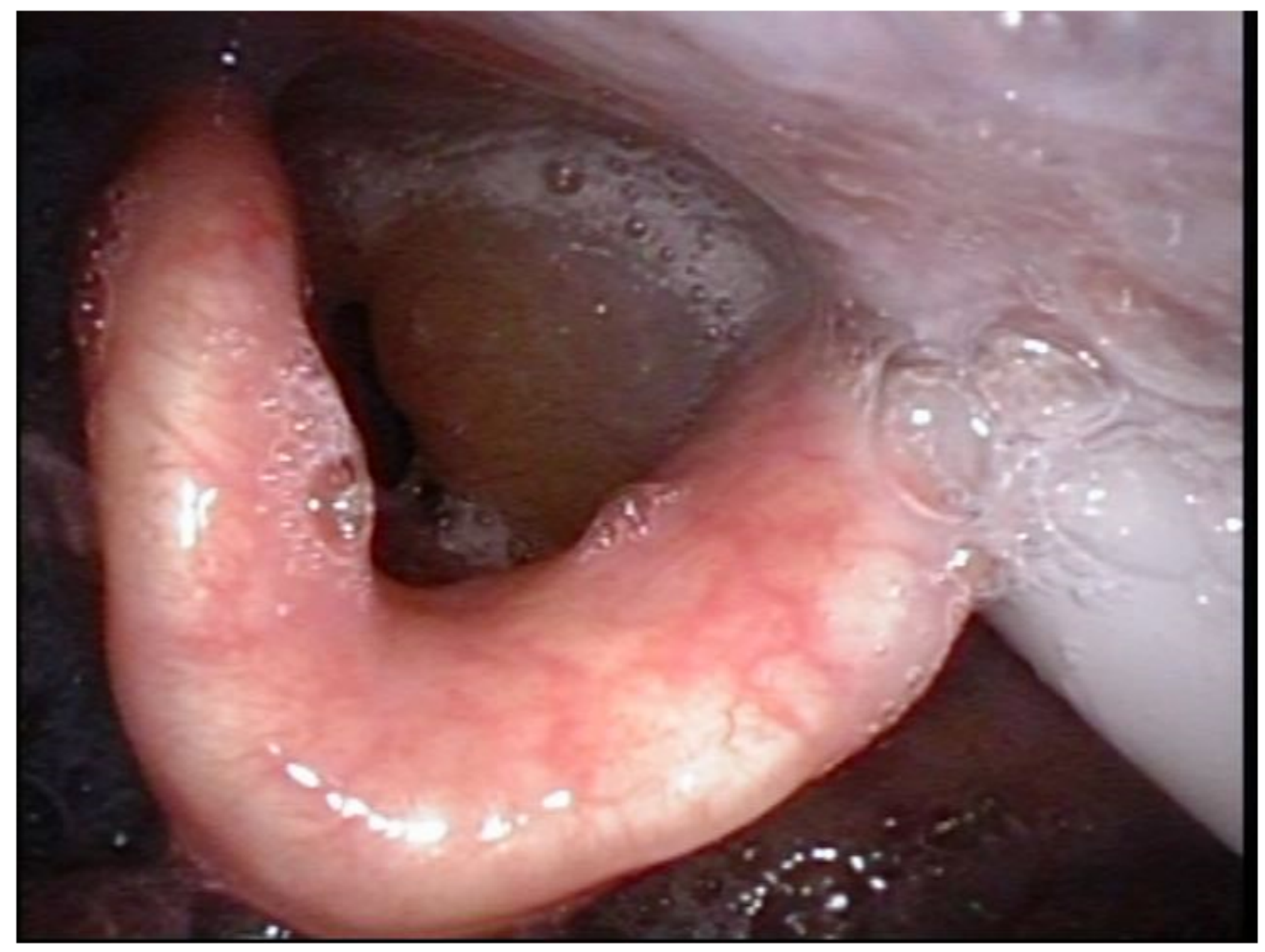

\section{Figure 2}

title: laryngeal findings before removal of nasointestinal ileus tube Legend: nasointestinal ileus tube at left side of hypopharynx through cervical esophagus and saliva retention around larynx 


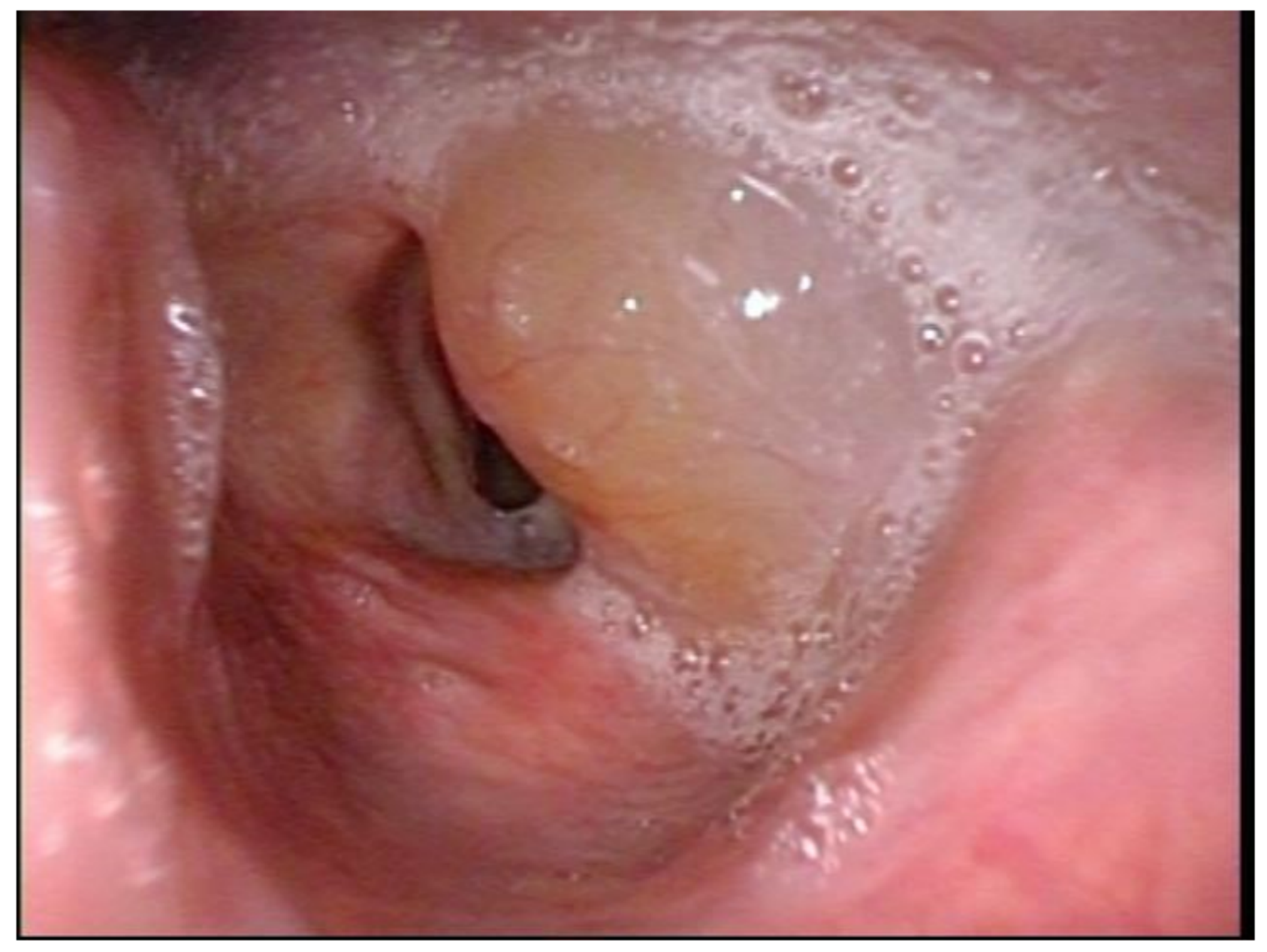

Figure 3

title: laryngeal findings immediately after removal Legend: left arytenoid edema and reddish was seen clearly 


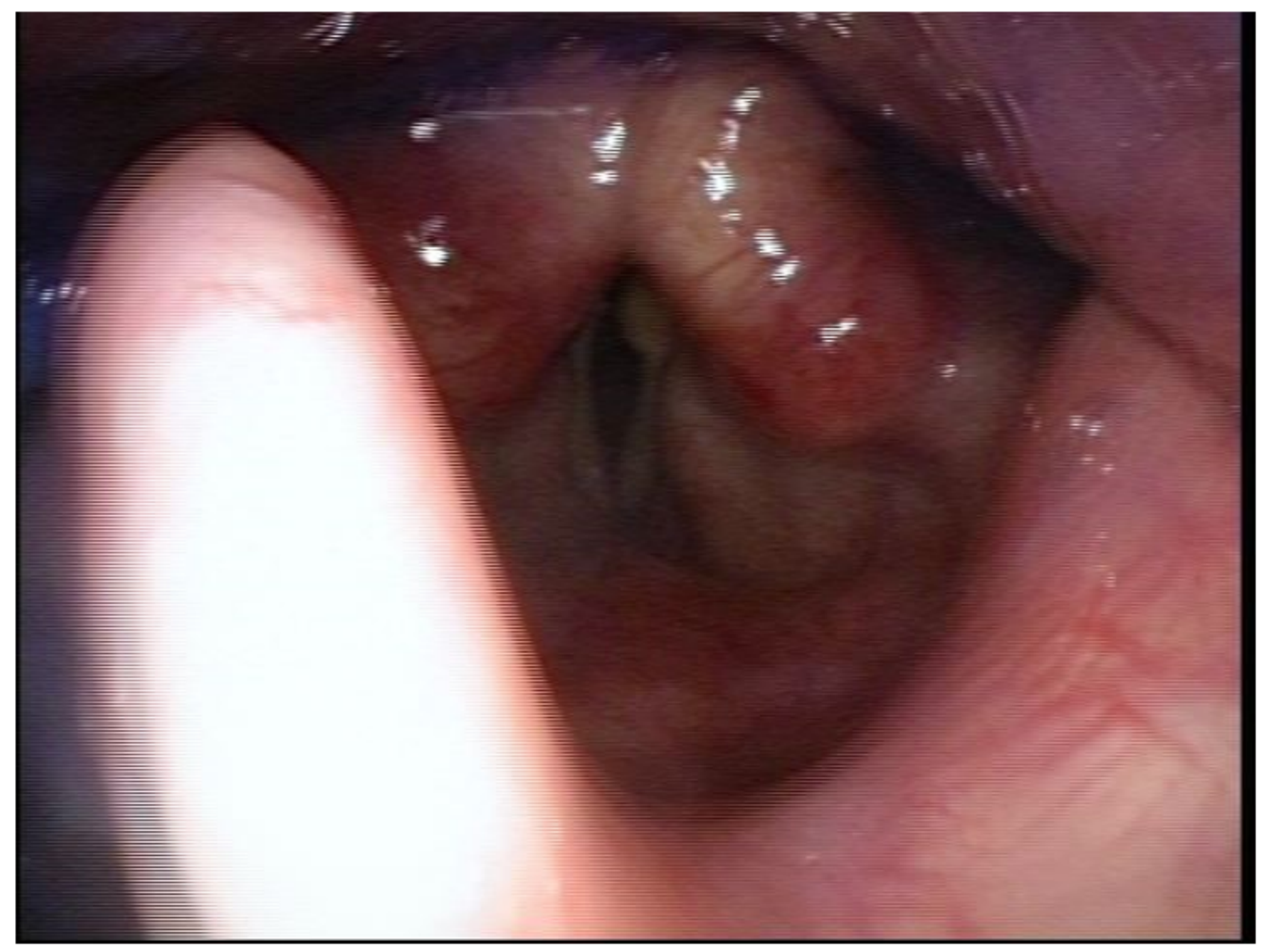

\section{Figure 4}

title: seven days after removal and treatment legend: left arytenoid edema and reddish was improved significantly

\section{Supplementary Files}

This is a list of supplementary files associated with this preprint. Click to download.

- CAREChecklistofinformationtoincludewhenwritingacasereport.docx 